\title{
Assessment of immunoglobulins free light chains in serum and urine of patients with system sclerosis: novel biomarkers for activity disease
}

\author{
Antonietta Gigante ${ }^{1}$, Chiara Pellicano ${ }^{1}$, Giorgia Leodori ${ }^{1}$, Cecilia Napodano $^{2}$, Lorenzo \\ Vantaggio $^{1}$, Francesca Gulli ${ }^{3}$, Mariapaola MARINO ${ }^{4}$, Marcella Visentini ${ }^{5}$, Edoardo \\ Rosato $^{1}$, and Umberto Basile ${ }^{2}$ \\ ${ }^{1}$ Sapienza University of Rome \\ ${ }^{2}$ Policlinico Universitario Agostino Gemelli \\ ${ }^{3}$ Ospedale Generale di Zona Madre Giuseppina Vannini \\ ${ }^{4}$ Universita Cattolica del Sacro Cuore \\ ${ }^{5}$ Universita degli Studi di Roma La Sapienza Facolta di Medicina e Odontoiatria
}

February 25, 2021

\begin{abstract}
Free light chains (FLC), considered a biomarker of B cell activity, are frequently elevated in different systemic inflammatoryautoimmune diseases. As systemic sclerosis (SSc) clinical course may be variable, this study aimed to assess FLCs levels in serum and urine of affected individuals, as biomarkers of disease activity. We assessed FLC levels in serum and urine of 72 SSc patients and 30 healthy controls (HC). Results were analyzed in comparison with overall clinical and laboratory findings, disease activity index (DAI) and disease severity scale (DSS). SSc patients displayed increased levels of $\mathrm{k}$ and $\lambda$ FLC in serum, significantly higher than $\mathrm{HC}(\mathrm{p}=0.0001)$ alongside with the mean levels of free $\mathrm{k} / \lambda$ ratio and of the $\mathrm{k}+\lambda$ sum $(\mathrm{p}=0.0001)$. In addition, SSc patients had significant higher levels in the urine of free $\mathrm{k}$ and of $\mathrm{k} / \lambda$ ratio than $\mathrm{HC}(\mathrm{p}=0.0001)$. SSc patients with increased $\mathrm{k}+\lambda$ sum in serum showed a statistically higher levels of erythro-sedimentation rate $(\mathrm{p}=0.034)$, C-reactive protein ( $\mathrm{p}=0.003)$, higher DAI ( $\mathrm{p}=0.024)$ and DSS $(\mathrm{p}=0.015)$ than SSc patients with normal levels of FLC. A positive linear correlation was found between serum levels of free $\mathrm{k}$ and DAI $(\mathrm{r}=0.29, \mathrm{p}=0.014)$. SSc patients with increased free $\mathrm{k}$ in urine had statistically higher DAI $(p=0.048)$ than SSc patients with normal level of free $\mathrm{k}$. The significant increased levels of FLC correlated with disease activity in SSc patients. Our results strengthen the role of FLC as useful biomarkers in clinical practice to early diagnosis and monitor disease activity with an improvement of SSc patients' management.
\end{abstract}

\section{Introduction}

Systemic sclerosis (SSc) is an autoimmune disease characterized by microvascular dysfunction, multi-systemic fibrosis and autoantibodies production. Immune dysregulation, vasculopathy and collagen accumulation with fibrosis in the skin and internal organs lead to major complications that negatively affect quality of life [1]. Although the pathogenesis of SSc remains poorly understood, activation and dysregulation of B cells play a key role. In SSc patients, abnormal immunological mechanisms promote survival and activation of self-reactive B cells, able to secrete inflammatory mediators and/or profibrotic cytokines inducing collagen secretion by fibroblast. Noteworthy, both serum and skin of SSc patients displayed increased levels of B lymphocyte stimulator (BAFF), a B cell survival factor that supports autoreactive B cells and prevents their deletion [2]. B-cell activation causes polyclonal synthesis of immunoglobulins and release of circulating Immunoglobulin- (Ig-) free light chains in serum (sFLC). FLCs, produced in slight excess of heavy chains 
during the synthesis of intact Ig by plasma cells, have a short half-life of $2-6 \mathrm{~h}$ in serum, due to a rapid removal by the kidneys: more than $99 \%$ of sFLC, filtered by the glomerulus, is reabsorbed from the cells of the proximal convoluted tubule resulting in the traces amounts in the urine (10-30 mg/day) [3]. Therefore, in subjects with normal kidney function, their serum levels can be considered as a direct biomarker of B cell activity, which explains the growing interest of clinicians. More important, the well-demonstrated FLC contribution to inflammation in experimental disease models sparked a new light into their pathogenic role in different chronic autoimmune-based inflammatory diseases [4]. An increased level of polyclonal sFLC, described in several autoimmune diseases (ADs), may represent a reliable potential biomarker of disease evolution or remission [5]. In SSc high sFLC is independently associated with interstitial lung disease (ILD), activity and severity disease [6].

Inflammatory/autoimmune-related symptoms complained by corona virus disease 2019 (COVID-19) patients, reflect the strong pathogenetic association between the severe acute syndrome corona virus2 (SARS-CoV-2) infection and autoimmunity [7, 8]. COVID-19 subsequent effects of an inflammatory-immune dysregulation significantly impaired the management of chronic rheumatic diseases, including systemic sclerosis. Cytokines storm cascade virus-triggered raises the possibility of severe endotheliopathy with a higher risk, in SSc patients, of worsening progression into an endothelial dysfunction [9].

To our knowledge, only two reports assessed sFLC levels in SSc patients but none regarding urine FLC (u-FLC) and their potential role in the SSc $[6,10]$

In this study, we aimed to analyze both serum and urine FLC levels in SSc patients in comparison healthy controls (HC) and to evaluate their correlations with activity and severity of disease.

\section{Materials and Methods}

\section{Patients and clinical assessment}

We enrolled 72 SSc patients [F=63, median age 55 years (IQR 46-65)], fulfilling the American College of Rheumatology/European League Against Rheumatism Collaborative Criteria for SSc [11]. According to Le Roy et al, 33 out of 72 Thirty-three (45.8\%) showed diffuse cutaneous SSc (dcSSc) and 39 out of 72 $(54.2 \%)$ limited cutaneous SSc (lcSSc) [12]. Demographic and clinical features of SSc patients are shown in Table 1. We also enrolled in the study $30 \mathrm{HC}$ matched for sex and age were. Exclusion criteria were renal failure, monoclonal gammopathies and hematological malignancies, immunosuppressive therapy in the last six months, pregnancy, and breastfeeding. Informed written consent was obtained from all the participants and the study was conducted according to the Declaration of Helsinki.

Demographic and clinical features were recorded. Disease subset [12], disease duration, nailfold videocapillaroscopy (NVC) pattern (early, active, late) [13], disease activity index (DAI) [14], disease severity scale (DSS) [15] and modified Rodnan skin score (mRSS) [16] were evaluated.

In the evaluation of SSc, DAI consists of variables among which skin thickening, digital ulcers, impaired single breath carbon monoxide diffusing capacity, tendon friction rubs and C-reactive protein (CRP) while DSS measures disease severity in organ systems from general health to specific organ involvement.

Renal function was calculated using the Chronic Kidney Disease Epidemiology Collaboration (CKD-EPI) equation to estimate glomerular filtration rate (eGFR) and serum creatinine was measured [17]. Moreover, all patients had an eGFR [?]60 $\mathrm{mL} / \mathrm{min} / 1.73 \mathrm{~m}^{2}$.

\section{Laboratory assessment}

Antinuclear antibodies detection by the indirect immunofluorescence assay (IIFA) was performed using HEp-2 cells (Menarini, Florence, Italy) and antigen specificity was determined by ELISA test. Erythrocyte sedimentation rate (ESR), CRP, C3, uric acid, serum creatinine ( $\mathrm{sCr}$ ) and urinalysis were evaluated.

The serum and urine were collected for the determinations of FLC concentrations on OPTILITE instruments (The Binding Site Group Ltd, Birmingham, UK). The quantitative detection of FLC has been obtained using 
the latex particle enhanced Freelite $\AA \mathrm{k}$ and $\lambda$ immunoassays (The Binding Site Group Ltd, Birmingham, UK) following the manufacturer's instructions.

The lower limit of quantification was $0.1 \mathrm{mg} / \mathrm{L}$. The immunoassay consisted of two separate measurements in serum, for free $\mathrm{k}$ (normal range: $3.3-19.4 \mathrm{mg} / \mathrm{L}$ ) and free $\lambda$ (normal range: $5.7-26.3 \mathrm{mg} / \mathrm{L}$ ). A ratio of $\mathrm{k} / \lambda$ $<0.26$ or $>1.65$ is abnormal, according to the manufacturer's recommendations. In urine, the normal value of free $\mathrm{k}$ is $0.39-15.1 \mathrm{mg} / \mathrm{L}$ and free $\lambda$ is $0.81-10.1 \mathrm{mg} / \mathrm{L}$. A ratio of $\mathrm{k} / \lambda \mathrm{uFLC}>1.80$ is considered abnormal. Samples were thawed only once and immediately assayed in a single batch, following the manufacturer's instructions. All the determinations were performed by an operator without knowledge of the clinical information of the handled sample. Each sample was tested twice to minimize eventual discrepancies, and all tests were performed in the same laboratory with the same instruments.

\section{Ethical Consideration}

The ethic committee of institution (Azienda Ospedaliera Universitaria, Policlinco Umberto I, Università "La Sapienza", Rome, Italy ) approved the study (ID: 5435, CE, SAPIENZA). All patients gave written informed consent to the use of their clinical and serological data in this study. The whole study was conducted according to the Declaration of Helsinki, as revised in 2013.

\section{Statistical Analysis}

SPSS version 25.0 software was used for statistical analysis and all results are expressed as median and interquartile range (IQR). The coefficient of skewness and the Shapiro-Wilk test were used to evaluate normal distribution of data. Group comparisons were made by Mann-Whitney test. The chi-square test or Fisher's exact test, as appropriate, were used to compare categorical variables. Pearson product-moment correlation coefficient or Spearman's rank correlation coefficient, as appropriate, were used to test for an association between numerical variables. $P$-values $<0.05$ were considered significant.Results

Free serum and urine light chains in SSc patients and $H C$

The median value of serum and urine FLC in SSc patients and HC are shown in Table 2. The median value of serum free $\mathrm{k}$ and free $\lambda$ levels, $\mathrm{k}+\lambda$ sum and $\mathrm{k} / \lambda$ ratio was significantly higher in SSc patients compared with HC. SSc patients displayed significantly higher mean serum levels of free $\mathrm{k}(23.5 \mathrm{mg} / \mathrm{L}$ vs $8.1 \mathrm{mg} / \mathrm{L}, p$ $=0.0001)$ and free $\lambda(17.5 \mathrm{mg} / \mathrm{L}$ vs $10.1 \mathrm{mg} / \mathrm{L}, p=0.0001)$ than HC. Free $\mathrm{k}$ serum levels were higher than $19.4 \mathrm{mg} / \mathrm{L}$ in $57 / 72(79.2 \%)$ SSc patients while none of the HC displayed free $\mathrm{k}$ in serum higher than 19.4 $\mathrm{mg} / \mathrm{L}(p=0.0001)$. Serum free $\lambda$ levels were higher than $26.3 \mathrm{mg} / \mathrm{L}$ in $7 / 72(9.7 \%) \mathrm{SSc}$ patients while none of the HC showed serum free $\lambda$ higher than $26.3 \mathrm{mg} / \mathrm{L}(p=0.102)$. The median of $\mathrm{k} / \lambda$ sFLC ratio (1.4 vs $0.8)$ and the median of $\mathrm{k}+\lambda$ sFLC $(40.5 \mathrm{mg} / \mathrm{L}$ vs $19.6 \mathrm{mg} / \mathrm{L})$ were significantly higher in SSc patients if compared with HC $(p=0.0001)$. The $\mathrm{k} / \lambda$ sFLC ratio was higher than 1.65 in $22 / 72(30.6 \%)$ SSc patients while none of the HC presented $\mathrm{k} / \lambda \mathrm{sFLC}$ ratio higher than $1.65(p=0.0001)$.

In addition, SSc patients had statistically significant higher levels in urine of free k-uFLC $(13.5 \mathrm{mg} / \mathrm{L}$ vs 6.1 $\mathrm{mg} / \mathrm{L}, p=0.0001)$ than HC. There was no difference in the mean value of $\lambda$-uFLC between SSc patients and $\mathrm{HC}(2.1 \mathrm{mg} / \mathrm{L}$ vs $2.4 \mathrm{mg} / \mathrm{L}, p=0.453]$. Urine free $\mathrm{k}$ levels were higher than $15.1 \mathrm{mg} / \mathrm{L}$ in $32 / 72(44.4 \%) \mathrm{SSc}$ patients while none of the $\mathrm{HC}$ presented higher levels of free $\mathrm{k}(\mathrm{p}=0.0001)$; only $1 / 72 \mathrm{SSc}$ patient (1.4\%) had urine free $\lambda$ levels higher than $10.1 \mathrm{mg} / \mathrm{L}$ and none of the HC presented higher levels of $\lambda(p=0.706)$. In SSc patients, the mean level of the $\mathrm{k} / \lambda$ ratio in urine was higher than in $\mathrm{HC}$ (6.7 vs $2.1, p=0.00019$. The urine $\mathrm{k} / \lambda$ ratio was higher than 1.80 in 63/72 (87.5\%) SSc patients and in $19(63.3 \%) \mathrm{HC}(p=0.007)$.

The mean value of the urine $\mathrm{k}+\lambda$ sum $(16.5 \mathrm{mg} / \mathrm{L}$ vs $8.1 \mathrm{mg} / \mathrm{L}, p=0.001)$ was significantly higher if compared with HC.

\section{Correlation between serum and urine free light chains and clinical correlates in SSc patients}

No significant difference was found between sFLC and uFLC and disease subsets, NVC and autoantibody specificity $(p>0.05)$. SSc patients with increased $\lambda$-sFLC had statistically higher serum levels of ESR [43 $\mathrm{mm} / \mathrm{h}(25 \mathrm{~mm} / \mathrm{h}-74 \mathrm{~mm} / \mathrm{h})$ vs $16 \mathrm{~mm} / \mathrm{h}(9 \mathrm{~mm} / \mathrm{h}-32 \mathrm{~mm} / \mathrm{h}), \mathrm{p}=0.005]$ and CRP [5600 mcg/l (3800 mcg/l 
- $16300 \mathrm{mcg} / \mathrm{l})$ vs $1500 \mathrm{mcg} / \mathrm{l}(800 \mathrm{mcg} / \mathrm{l}-3100 \mathrm{mcg} / \mathrm{l}), \mathrm{p}=0.008]$ than SSc patients with $\lambda$-sFLC under 26.3 $\mathrm{mg} / \mathrm{L}$ cut-off.

SSc patients with increased serum $\mathrm{k}+\lambda$ sum had statistically higher serum levels of ESR $[23 \mathrm{~mm} / \mathrm{h}(16$ $\mathrm{mm} / \mathrm{h}-43 \mathrm{~mm} / \mathrm{h})$ vs $16 \mathrm{~mm} / \mathrm{h}(9 \mathrm{~mm} / \mathrm{h}-30 \mathrm{~mm} / \mathrm{h}), \mathrm{p}=0.034]$ and CRP [2800 mcg/l $(1900 \mathrm{mcg} / \mathrm{l}-6050$ $\mathrm{mcg} / \mathrm{l})$ vs $1200 \mathrm{mcg} / \mathrm{l}(700 \mathrm{mcg} / \mathrm{l}-2900 \mathrm{mcg} / \mathrm{l}), \mathrm{p}=0.003]$ than $\mathrm{SSc}$ patients with normal levels of total sFLC. Moreover, SSc patients with increased serum $\mathrm{k}+\lambda$ sum had statistically higher DAI $[2.5$ (1.55 - 3.86) vs 1.5 (0.6 - 2.5), $\mathrm{p}=0.024]$ and DSS $[6(5-7)$ vs $5(3-6), \mathrm{p}=0.015]$ than SSc patients with normal levels of total sFLC.

A trend of a positive linear correlation was found between k-sFLC and DAI $(r=0.290, p=0.014)$.

SSc patients with increased k-uFLC had statistically higher DAI [1.9 (1.2 - 3.3) vs 1.4 (0.5 - 2.13), p=0.048] than SSc patients with k-uFLC under $15.1 \mathrm{mg} / \mathrm{L}$.

No differences emerged in patients diagnosed with arterial hypertension and both serum and urinary FLC $(p>0.05)$.

\section{Discussion}

Elevated levels of sFLC have been found in a variety of ADs, including systemic lupus erythematosus, rheumatoid arthritis, Sjögren's syndrome, ankylosing spondylitis, psoriatic arthritis, vasculitis although many studies included a small number of patients $[5,18,19]$.

In these ADs, sFLC correlated strongly with inflammatory mediators, activity and severity index demonstrating their potential for predicting disease activity [19, 20].

Few studies have quantified the FLC in SSc and only one in the serum [10]. Bosello et al found elevated ksFLC vs HC that correlated with restrictive lung disease, disease activity and inflammatory biomarkers such as ESR, CRP and interleukin-6 (IL-6) [6]. IL-6 is produced by activated B cells and the authors suggest that sFLC may play a role in the pathogenetic mechanisms of SSc. As multifunctional cytokine, IL-6 plays a wellrecognized role in inflammatory, immunoregulatory and haemopoietic responses. Thanks to a trans-signaling mechanism mediated by its soluble receptor, IL-6 may orchestrate a wide range of inflammatory-immune properties [21-23]. Among biological properties of IL-6, the stimulation of collagen synthesis by dermal fibroblasts is well recognized [24].

In fact, high levels of IL-6 are found in the skin and serum of SSc patients connecting the role of this cytokine in the onset of inflammation and fibrosis through the activation of B cell and the subsequent production of sFLC [25]. Moreover, Lanteri et al, analyzing $134 \mathrm{SSc}$ patients found a correlation between sFLC and BAFF levels [10] The BAFF family, play a pivotal fundamental role in B cell development, maturation, and survival and it is found higher in the skin and serum and of SSc patients [25].

Serum FLC is a marker of polyclonal activation and here we showed that in our patients both serum free $\mathrm{k}$ and $\lambda$ and $\mathrm{k}+\lambda$ sum correlate with ESR and CRP. In addition, a linear correlation was found between serum free $\mathrm{k}$ with DAI and DSS. In addition, when specific cut-off values for normal range of sFLC were considered, SSc patients with abnormal serum free $\mathrm{k}$ and $\mathrm{k}+\lambda$-sum showed a positive correlation with DAI and DSS.

Thus, supporting the role of B cell activation in the pathophysiology of SSc, an overproduction of FLCs may occur because of chronic immune stimulation. This fit well with the proposed role of FLC as a biomarker of B cell activity as suggested in many studies on Ads [5].

To our knowledge, this is the first study that includes the evaluation also of urinary FLC in patients with SSc.

The main result of our study is that urinary FLC levels were found to be elevated in comparison to the HC. Higher urine free $\mathrm{k}$ levels, $\mathrm{k}+\lambda$ sum, $\mathrm{k} / \lambda$ ratio $>1.80$ were found in SSc patients, while urine $\lambda$ levels were comparable to $\mathrm{HC}$. 
Since in SSc the clinical features are heterogeneous and disease course variable, the introduction of new biomarkers is crucial to early determine systemic complications.

Biomarkers are useful to predict disease activity and progression, to identify patients at high risk of flares and monitor response to treatment. In a large cohort of individual without plasma cell disorder, the findings of FLC levels above the normal range proved to be predictors of worse overall survival in the general population of individual without plasma cell disorders [26]. The urinary levels of polyclonal FLC strongly depend on the rate of production and serum concentrations, on the range of proteinuria, presence of tubular damage and the affinity of the tubules for all different FLC [27]. The system of reabsorption by the proximal tubular is very efficient but saturable. Measurement of uFLCs is most used in course of plasma cell malignancy as multiple myeloma, with an excess of monoclonal $\mathrm{k}$ or $\lambda$ FLC [28].

On the other hand, the clinical significance of polyclonal FLC is to monitor activity of the disease, especially in those characterized by activation of the B such as ADs and chronic inflammatory disorders [5].

In SSc, subclinical renal involvement is characterized by abnormal resistive index [29], isolated reduction in glomerular filtration rate (GFR) rate and reduced kidney reserve [30]. Livi et al evaluated the renal functional reserve from response of the kidney to an amino acid challenge in normotensive patients with normal renal function and no urinary abnormalities [31]. They found in SSc patients an abnormal activation of renal functional reserve (RFR). RFR is a parameter to measure the ability of the undamaged kidney to increase GFR in response to protein overload and it depends on the activation of preglomerular vasodilating mechanisms. In SSc, a functional derangement of vascular tone control is evident, favouring the prevalence of vasoconstrictor over vasodilating factors.

The lack of correlation between serum and urinary FLC suggests the kidney's inability to reabsorb the sFLC produced. It is well known that a high prevalence of silent renal changes is observed in SSc kidneys, including a reduced renal blood flow [32].

In clinical practice, the polyclonal elevations of FLCs are observed in patients with chronic kidney disease and high blood pressure [33]. However, in our study the mean value of eGFR in SSc patients was $93 \mathrm{ml} / \mathrm{min}$ and no differences were found between patients with and without arterial hypertension with both serum and urinary FLC levels. Thus, we can confirm that the clearance and loss of FLC is not GFR and comorbidity dependent.

The continuous reabsorption and accumulation of sFLC within the proximal tubule lumen led to inflammation, tubular cells apoptosis, activation of redox pathways and production of profibrotic cytokines [34, 35]. In the present study SSc patients with abnormal urine free $\mathrm{k}$ have higher DAI, although there is a weak positivity. The analysis of both urine and serum for the assessment of FLC levels offer a simplified route to evaluating the presence of activity and severity disease in ADs. The increased levels of uFLC in these patients could be the result of non-specific polyclonal B cell activation as occurs in other ADs.

The FLC production observed in different systemic rheumatic autoimmune diseases reflect the clone expansion of B cells with specific autoreactivities [4]. Due to their short half-life, FLC may be considered a direct biomarker of B cell activity, recently described also in organo-specific autoimmune disorders [36]. Increased FLC levels maybe a marker of disease severity and can be useful for therapeutic monitoring or to assess recurrences investigating and reporting the association between pathogenic viruses (SARS-Cov2) with the development of inflammatory condition in autoimmune diseases.

In conclusion, we suggest that both serum and urinary levels of FLC could be considered a reliable biomarker to early diagnosis and monitoring of disease activity, leading to an optimization of specific patients' management.

\section{References}

1. Varga J, Trojanowska M, Kuwana M. Pathogenesis of systemic sclerosis: recent insights of molecular and cellular mechanisms and therapeutic opportunities. J Scleroderma Relat Disord 2017; 2:137-52. 
2. Matsushita T, Hasegawa M, Yanaba K, et al. Elevated serum BAFF levels in patients with systemic sclerosis: enhanced BAFF signaling in systemic sclerosis B lymphocytes. Arthritis Rheum 2006; 54:192-201.

3. Basile U, Gulli F, Gragnani L, Napodano C, Pocino K, Rapaccini GL, Mussap M, Zignego AL. Free light chains: Eclectic multipurpose biomarker. J Immunol Methods. 2017; 451:11-19.

4. Gulli F, Napodano C, Marino M, Ciasca G, Pocino K, Basile V, Visentini M, Stefanile A, Todi L, De Spirito M, Rapaccini GL, Basile U. Serum immunoglobulin free light chain levels in systemic autoimmune rheumatic diseases. Clin Exp Immunol 2020; 2:163-171.

5. Napodano C, Pocino K, Rigante D, Stefanile A, Gulli F, Marino M, Basile V, Rapaccini GL, Basile U. Free light chains and autoimmunity. Autoimmun Rev 2019; 5:484-492.

6. Bosello S, Basile U, De Lorenzis E, Gulli F, Canestrari G, Napodano C, Parisi F, Pocino K, Di Mario C, Tolusso B, Ferraccioli G, Gremese E. Free light chains of immunoglobulins in patients with systemic sclerosis: correlations with lung involvement and inflammatory milieu. J Clin Pathol 2018; 7:620-625.

7. Halpert G, Shoenfeld Y. SARS-CoV-2, the autoimmune virus. Autoimmun Rev 2020; 12:102695.

8. Napodano C, Pocino K, Stefanile A, Marino M, Miele L, Gulli F, Basile V, Pandolfi F, Gasbarrini A, Rapaccini GL, Basile U. COVID-19 and hepatic involvement: The liver as a main actor of the pandemic novel. Scand J Immunol 2020; 15:e12977

9. Gupta L, Kharbanda R, Agarwal V, Misra DP, Agarwal V. Patient Perspectives on the Effect of the SARSCoV-2 Pandemic on Patients With Systemic Sclerosis: An International Patient Survey. J Clin Rheumatol 2021; 1:31-33.

10. van den Hoogen F, Khanna D, Fransen J, Johnson SR, Baron M, Tyndall A, A, Matucci-Cerinic M, Naden RP, Medsger TA Jr, Carreira PE, Riemekasten G, Clements PJ, Denton CP, Distler O, Allanore Y, Furst DE, Gabrielli A, Mayes MD, van Laar JM, Seibold JR, Czirjak L, Steen VD, Inanc M, KowalBielecka O, Müller-Ladner U, Valentini G, Veale DJ, Vonk MC, Walker UA, Chung L, Collier DH, Ellen Csuka M, Fessler BJ, Guiducci S, Herrick A, Hsu VM, Jimenez S, Kahaleh B, Merkel PA, Sierakowski S, Silver RM, Simms RW, Varga J, Pope JE. 2013 Classification criteria for systemic sclerosis: an American college of rheumatology/European league against rheumatism collaborative initiative. Ann Rheum Dis 2013; $72: 1747-55$.

11. LeRoy EC, Black C, Fleischmajer R, Jablonska S, Krieg T, Medsger TA, Rowell N, Wollheim F. Scleroderma (systemic sclerosis): classification, subsets and pathogenesis. J Rheumatol 1988; 15:202-05.

12. Cutolo M, Sulli A, Secchi ME, Paolino S, Pizzorni C. Nailfold capillaroscopy is useful for the diagnosis and follow-up of autoimmune rheumatic diseases. A future tool for the analysis of microvascular heart involvement? Rheumatology 2006; 45:43-46.

13. Valentini G, Iudici M, Walker UA, Jaeger VK, Baron M, Carreira P, Czirják L, Denton CP, Distler O, Hachulla E, Herrick AL, Kowal-Bielecka O, Pope J, Müller-Ladner U, Riemekasten G, Avouac J, Frerix M, Jordan S, Minier T, Siegert E, Ong VH, Vettori S, Allanore Y. The European Scleroderma Trials and Research group (EUSTAR) task force for the development of revised activity criteria for systemic sclerosis: derivation and validation of a preliminarily revised EUSTAR activity index. Ann Rheum Dis 2017; 76:270-76.

14. Medsger TA Jr, Silman AJ, Steen VD, Black CM, Akesso A, Bacon PA, Harris CA, Jablonska S, Jayson MI, Jimenez SA, Krieg T, Leroy EC, Maddison PJ, Russell ML, Schachter RK, Wollheim FA, Zacharaie H. A disease severity scale for systemic sclerosis: development and testing. J Rheumatol 1999; 26:2159-67.

15. Clements P, Lachenbruch P, Siebold J, White B, Weiner S, Martin R, et al. Inter and intraobserver variability of total skin thickness score (modified Rodnan TSS) in systemic sclerosis. J Rheumatol 1995; $22: 1281-85$. 
16. Gigante A, Rosato E, Massa R, Rossi C, Barbano B, Cianci R, Molinaro I, Amoroso A, Salsano F. Evaluation of Chronic Kidney Disease Epidemiology Collaboration equation to estimate glomerular filtration rate in scleroderma patients. Rheumatology (Oxford). 2012; 8:1426-31.

17. Bramlage CP, Froelich B, Wallbach M, Minguet J, Grupp C, Deutsch C, Bramlage P, Koziolek M, Müller GA. The significance and predictive value of free light chains in the urine of patients with chronic inflammatory rheumatic disease. Clin Rheumatol 2016; 12:2939-2946.

18. Aggarwal R, Sequeira W, Kokebie R, Mikolaitis RA, Fogg L, Finnegan A, Plaas A, Block JA, Jolly M. Serum free light chains as biomarkers for systemic lupus erythematosus disease activity. Arthritis Care Res (Hoboken) 201; 6:891-8.

19. Gottenberg JE, Miceli-Richard C, Ducot B, Goupille P, Combe B, Mariette X. Markers of B-lymphocyte activation are elevated in patients with early rheumatoid arthritis and correlated with disease activity in the ESPOIR cohort. Arthritis Res Ther 2009; 4:R114.

20. Lanteri A, Sobanski V, Langlois C, Lefèvre G, Hauspie C, Sanges S, Lambert M, Morell-Dubois S, Hatron PY, Hachulla E, Launay D, Dubucquoi S. Serum free light chains of immunoglobulins as biomarkers for systemic sclerosis characteristics, activity, and severity. Autoimmun Rev 2014; 9:974-80.

20. Scala E, Pallotta S, Frezzolini A, Abeni D, Barbieri C, Sampogna F, De Pità O, Puddu P, Paganelli R, Russo G. Cytokine and chemokine levels in systemic sclerosis: relationship with cutaneous and internal organ involvement. Clin Exp Immunol 2004; 3:540-6.

21. Bartoccioni E, Scuderi F, Marino M, Provenzano C. IL-6, monocyte infiltration and parenchymal cells. Trends Immunol 2003; 6:299-300;

22. Marino M, Scuderi F, Provenzano C, Scheller J, Rose-John S, Bartoccioni E. IL-6 regulates MCP-1, ICAM-1 and IL-6 expression in human myoblasts. J Neuroimmunol 2008; 1-2:41-8.

23. Marino M, Scuderi F, Ponte E, Maiuri MT, De Cristofaro R, Provenzano C, Rose-John S, Cittadini A, Bartoccioni E. Novel path to IL-6 trans-signaling through thrombin-induced soluble IL-6 receptor release by platelets. J Biol Regul Homeost Agents 2013; 3:841-52.

24. Sippl N, Faustini F, Rönnelid J, Turcinov S, Chemin K, Gunnarsson I, Malmström V. Arthritis in systemic lupus erythematosus is characterized by local IL-17A and IL-6 expression in synovial fluid. Clin Exp Immunol 2021.

25. Matsushita T, Hasegawa M, Yanaba K, Kodera M, Takehara K, Sato S. Elevated serum BAFF levels in patients with systemic sclerosis: enhanced BAFF signaling in systemic sclerosis B lymphocytes. Arthritis Rheum 2006; 1:192-201.

26. Dispenzieri A, Katzmann JA, Kyle RA, Larson DR, Therneau TM, Colby CL, Clark RJ, Mead GP, Kumar S, Melton LJ 3rd, Rajkumar SV. Use of nonclonal serum immunoglobulin free light chains to predict overall survival in the general population. Mayo Clin Proc 2012; 6:517-23.

27. Hutchison CA, Harding S, Hewins P. Quantitative assessment of serum and urinary polyclonal free light chains in patients with chronic kidney disease. Clin J Am Soc Nephrol 2008; 6:1684-1690.

28. Nakano T, Nagata A, Takahashi H. Ratio of urinary free immunoglobulin light chain kappa to lambda in the diagnosis of Bence Jones proteinuria. Clin Chem Lab Med 2004; 4:429-434.

29. Rosato E, Gigante A, Barbano B, Gasperini ML, Cianci R, Muscaritoli M. Prognostic Factors of Renal Involvement in Systemic Sclerosis. Kidney Blood Press Res 2018; 3:682-689.

30. Shanmugam VK, Steen VD. Renal disease in scleroderma: an update on evaluation, risk stratification, pathogenesis and management. Curr Opin Rheumatol 2012; 6:669-76. 
31. Livi R, Teghini L, Pignone A, Generini S, Matucci-Cerinic M, Cagnoni M. Renal functional reserve is impaired in patients with systemic sclerosis without clinical signs of kidney involvement. Ann Rheum Dis $2002 ; 8: 682-6$.

32. Clements PJ, Lachenbruch PA, Furst DE, Maxwell M, Danovitch G, Paulus HE. Abnormalities of renal physiology in systemic sclerosis. A prospective study with 10 year follow up. Arthritis Rheum 1994; 37:67-74.

33. Hutchison CA, Harding S, Hewins P, Mead GP, Townsend J, Bradwell AR, Cockwell P. Quantitative assessment of serum and urinary polyclonal free light chains in patients with chronic kidney disease. Clin $\mathrm{J}$ Am Soc Nephrol 2008; 6:1684-90.

34. Basnayake K, Stringer SJ, Hutchison CA, Cockwell P. The biology of immunoglobulin free light chains and kidney injury. Kidney Int 2011; 79:1289-301.

35. Liu Y. New insights into epithelial-mesenchymal transition in kidney fibrosis. J AmSoc Nephrol 2010; 21:212-22.

36. Basile U, Marino M, Napodano C, Pocino K, Alboini PE, Gulli F, Evoli A, Provenzano C, Bartoccioni E. Serological Immunoglobulin-Free Light Chain Profile in Myasthenia Gravis Patients. J Immunol Res 2018; 2018: 9646209 .

Table 1. Demographic and clinical features of SSc patients.

\begin{tabular}{ll}
\hline Age, years, median and IQR & $55(46-65)$ \\
Female, n (\%) & $63(87.5)$ \\
dcSSc, n (\%) & $33(45.8)$ \\
Disease duration, years, median and IQR & $11(6-20)$ \\
mRSS, median and IQR & $13(7-18)$ \\
SSc-specific autoantibodies: & \\
Anti-topoisomerase I, n (\%) & $33(45.8)$ \\
Anti-centromere, n (\%) & $24(33.3)$ \\
Anti-RNA polymerase III, n (\%) & $4(5.6)$ \\
None, n (\%) & $11(15.3)$ \\
DAI, median and IQR & $1.5(0.8-2.9)$ \\
DSS. median and IQR & $5(4-6)$ \\
Telangiectasias, n (\%) & $38(52.8 \%)$ \\
ESR, mm/h, median and IQR & $19(12-34)$ \\
CRP, mcg/L, median and IQR & $1600(800-3500)$ \\
C3, mg/L, median and IQR & $1045(925-1180)$ \\
Nailfold capillaroscopic pattern: & \\
Early, n (\%) & $13(18.1)$ \\
Active, n (\%) & $23(31.9)$ \\
Late, n (\%) & $36(50)$ \\
sCr, mg/dL, median and IQR & $0.8(0.6-0.9)$ \\
eGFR, mL/min, median and IQR & $93(80-108)$ \\
Arterial hypertension, n (\%) & $22(30.6 \%)$ \\
\hline
\end{tabular}

SSc:systemic sclerosis; dcSSc:diffuse cutaneous systemic sclerosis; mRSS: modified Rodnan Skin Score; DAI:Disease Activity Index; DSS:Disease Severity Scale; sCR:serum creatinine; eGFR: estimated glomerular filtration rate.

Table 2. Serum and urine free light chains in SSc Patients and healthy controls. 


\begin{tabular}{|c|c|c|c|}
\hline & SSc & $\mathrm{HC}$ & $\mathrm{p}$ \\
\hline k-sFLC levels, mg/L, median and IQR & $23.5(19.7-28.4)$ & $8.1(7.1-10)$ & $p=0.0001$ \\
\hline$\lambda-\sigma \Phi \Lambda^{\prime \prime} \lambda \varepsilon \varepsilon \lambda \varsigma, \mathrm{mg} / \mathrm{L}$, median and IQR & $17.5(13.2-20.7)$ & $10.1(7.9-16.2)$ & $p=\mathbf{0 . 0 0 0 1}$ \\
\hline$\varkappa / \lambda \sigma \Phi \Lambda^{\prime \prime} \rho \alpha \tau \iota \boldsymbol{o}$, median and IQR & $1.4(1.2-1.8)$ & $0.8(0.6-0.9)$ & $p=0.0001$ \\
\hline$\varkappa-\sigma \boldsymbol{\Phi} \boldsymbol{\Lambda}^{\mathrm{*}}+\lambda-\sigma \boldsymbol{\Phi} \boldsymbol{\Lambda}^{\mathrm{n}} \lambda \boldsymbol{\varepsilon} \varepsilon \lambda \varsigma, \mathrm{mg} / \mathrm{L}$, median and IQR & $40.5(35.6-46.4)$ & $19.6(15.8-24.7)$ & $p=0.0001$ \\
\hline k-sFLC >19.4 mg/L, n (\%) & $57(79.2)$ & $0(0)$ & $p=0.0001$ \\
\hline$\lambda-\sigma \boldsymbol{\Phi} \boldsymbol{\Lambda}^{*}>\mathbf{2 6 . 3} \mathrm{mg} / \mathrm{L}, \mathrm{n}(\%)$ & $7(9.7)$ & $0(0)$ & $p=0.102$ \\
\hline$\varkappa / \lambda \sigma \Phi \Lambda^{\prime \prime}$ p $\alpha \tau \iota \circ>1.65, \mathrm{n}(\%)$ & $22(30.6)$ & $0(0)$ & $p=\mathbf{0 . 0 0 1}$ \\
\hline k-uFLC levels, mg/L, median and IQR & $13.5(4.8-22.5)$ & $6.1(3.6-7.6)$ & $p=\mathbf{0 . 0 0 0 1}$ \\
\hline$\lambda-\cup \Phi \Lambda^{\prime \prime} \lambda \varepsilon \varepsilon \lambda \varsigma, \mathrm{mg} / \mathrm{L}$, median and IQR & $6-3.6)$ & $2.4(1.3-3.1)$ & $p=0.453$ \\
\hline k-uFLC >15.1 mg/L, n (\%) & $32(44.4)$ & $0(0)$ & $p=\mathbf{0 . 0 0 0 1}$ \\
\hline$\lambda-\cup \Phi \Lambda^{*}>10.1 \mathrm{mg} / \mathrm{L}, \mathrm{n}(\%)$ & $1(1.4)$ & $0(0)$ & $p=0.706$ \\
\hline 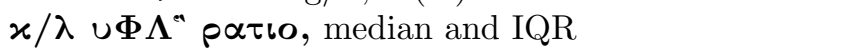 & $6.7(3.4-11.7)$ & $2.1(1.8-3.2)$ & $p=0.0001$ \\
\hline$\varkappa-\cup \Phi \Lambda^{\prime \prime}+\lambda-\cup \Phi \Lambda^{\prime \prime} \lambda \varepsilon \varepsilon \lambda \varsigma, m g / L$, median and IQR & $16.5(6-25.6)$ & $8.1(5.4-10.7)$ & $p=0.001$ \\
\hline$\varkappa / \lambda \cup \Phi \Lambda^{\prime \prime} \rho \alpha \tau \iota 0>1.80, \mathrm{n}(\%)$ & $63(87.5)$ & $19(63.3)$ & $p=\mathbf{0 . 0 0 7}$ \\
\hline
\end{tabular}

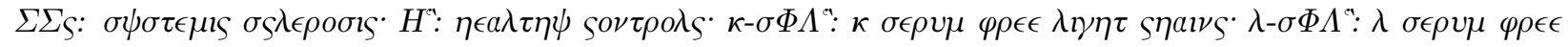

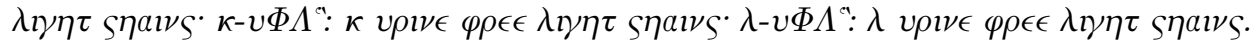

Figure 1. Free light chains distributions in in SSc Patients and healthy controls

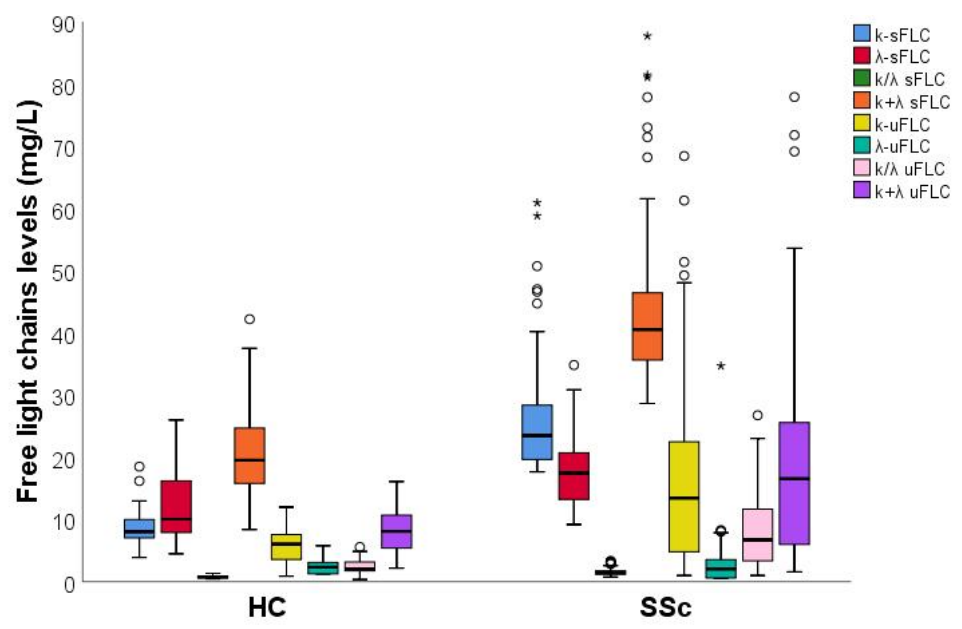

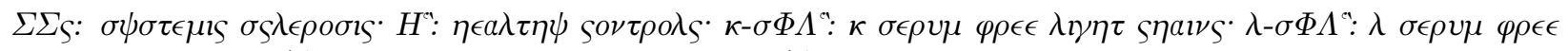

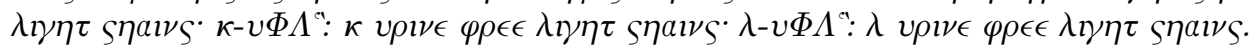

